\title{
Fases das tecnologias digitais na exploração matemática em sala de aula: das calculadoras gráficas aos celulares inteligentes
}

Phases of digital technologies in the mathematical exploitation in a classroom: from graphic calculators to smartphones

\author{
Rejane Waiandt Schuwartz de Carvalho Faria ${ }^{1}$ \\ Laís Aparecida Romanello² \\ Nilton Silveira Domingues ${ }^{3}$
}

\section{Resumo}

Este artigo apresenta pesquisas relacionadas ao uso de tecnologias na exploração matemática nas diferentes fases das tecnologias digitais. A divisão dessas fases inicia-se por volta dos anos 1980 e compreendem os dias atuais, de modo a se formar quatro fases que não são disjuntas. Para isso, enfatiza-se uma mesma atividade investigativa nas mídias calculadora gráfica, computadores e celulares inteligentes, discutindo as possibilidades e limitações de cada mídia. Aponta-se os celulares inteligentes como a principal tendência futura no que tange as tecnologias digitais em sala de aula de Matemática na Educação Básica. Com a discussão realizada é possível afirmar que o sucesso de uma atividade com o uso de tecnologias se dá a partir de uma atividade bem elaborada, que favoreça a investigação e a criação de conjecturas pelos alunos. Além disso, fatores como pouca formação do professor no que tange o uso das tecnologias para o ensino da matemática, estrutura curricular não flexível e a dificuldade na elaboração de atividades com tecnologias, geram barreiras no trabalho do professor.

Palavras chave: calculadora gráfica; software dinâmico de matemática; celular inteligente; educação matemática.

\section{Abstract}

This paper reports researches related to the use of Technologies in mathematical exploration in different phases of digital technologies. These phases begins in the eighties and go through these days, in a way that each phase is not separated from the other. For this purpose, we emphasize one activity, which was investigated in different media like graphic calculators, computers and smartphones, discussing the possibilities and limitations of each media. We stress that smartphones are the biggest trend in digital technologies in Basic Mathematics Education. With the discussion carried out we point that the success of

\footnotetext{
${ }^{1}$ Universidade Federal do Pará | rejanefaria@ufpa.com

2 Universidade Estadual Paulista | laisromanello@gmail.com

${ }^{3}$ Universidade Estadual Paulista | niltonsdomingues@gmail.com
} 
one activity with the use of technology is related to its preparation, when it favours the investigation and creation of conjectures to the students. Besides, factors like lack of teacher training to the use of technology when teaching Mathematics, rigid curriculum and difficulties while preparing activities with technologies create barriers to teachers.

Keywords: graphic calculator; dynamic mathematics software; smartphone; mathematics education.

\section{Introdução}

Ao se realizar pesquisa com diferentes tecnologias em Educação Matemática junto ao GPIMEM ${ }^{4}$, nota-se que muitos professores da Educação Básica buscam incorporar o uso de Tecnologias em aulas de Matemática. Entretanto, encontram barreiras como falta de equipamentos, pouco apoio da gestão escolar ou mesmo formação inicial ou continuada deficitária nessa temática, não sabendo encontrar ou desenvolver atividades ou mesmo não tendo tempo de modificar sua prática devido à extensa jornada de trabalho que agrega grande quantidade de aulas (PERALTA, 2015; BRAGA, 2016). Com a finalidade de auxiliar interessados nessa temática, neste artigo, discute-se o uso de tecnologias, além de exemplificar uma investigação acerca da temática de funções quadráticas em diferentes mídias relativamente acessíveis, tais como as calculadoras gráficas, os computadores e os celulares inteligentes ${ }^{5}$, de modo a destacar as potencialidades e limitações de cada mídia.

Desde a década de 1980 a sociedade está passando por uma notável reorganização social, devido aos avanços tecnológicos de cunho digital (BORBA; SCUCUGLIA; GADANIDIS, 2014; BORBA; PENTEADO, 2001; FARIA, 2016; MALTEMPI, MENDES, 2016; ROMANELLO, 2016; VALENTE, 1993).

Ao utilizar o termo tecnologias, entende-se como "[...] o conjunto de conhecimentos e princípios científicos que se aplicam ao planejamento, à construção e à utilização de um equipamento em um determinado tipo de atividade" (KENSKI, 2013, p. 24), ou seja, os primórdios da humanidade já interagiam com as tecnologias mais variadas como fogo, madeira e metal. Contudo, nas últimas décadas os dias são marcados por uma grande quantidade virtual de informações, devido ao processo de popularização das Tecnologias Digitais, que repercute na história da informação e da própria humanidade (TORQUATO, 2008). Estão sendo utilizadas, com crescente frequência, a informática, o computador, o celular inteligente, a internet e outras Tecnologias Digitais (OZAKl; VASCONCELOS, 2008).

Embora não se possa negar a influência das Tecnologias Digitais no cotidiano dos mais diversos setores da sociedade, Maltempi e Mendes (2016) discutem que, "[...] estranhamente, a sala de aula pouco mudou nas últimas décadas" (MALTEMPl; MENDES, 2016, p. 2). Ou seja, não é difícil notar que a organização da mobília, os recursos disponíveis, o papel do professor e a postura dos alunos, muitas vezes continuam praticamente inalteradas, assim como a forma que ocorre o andamento das aulas, geralmente de modo tradicional, dispondo-se apenas de lousa, giz e livro didático (CHINELLATO, 2014; FARIA et al., 2016).

\footnotetext{
${ }^{4}$ O Grupo de Pesquisa em Informática, outras Mídias e Educação Matemática, consolidado há 24 anos, é coordenado pelo Prof. Dr. Marcelo de Carvalho Borba na Unesp - Rio Claro. http://igce.rc.unesp.br/\#!/gpimem.

${ }^{5}$ Neste artigo, tanto o termo "celular" quanto "celular inteligente", refere-se ao smartphone.
} 
Conquanto a sala de aula pouco tenha mudado, Oliveira e Marcelino (2015) alertam que a reorganização do meio, atua de diversas formas na vida dos estudantes, e que "[...] a maneira de pensar destes mesmos alunos sofre influência decisiva das mídias " (OLIVEIRA; MARCELINO, 2015, p. 819). Um primeiro passo para tentar mudar a sala de aula, seria o aproveitamento de recursos disponíveis na escola ou mesmo nos alunos, como é o caso do celular que se faz muito presente nas salas de aula.

Na década de 1990, D’Ambrosio nos alertou que

Será essencial para a escola estimular a aquisição, a organização, a geração e a difusão do conhecimento vivo, integrado nos valores e expectativas da sociedade. Isso será impossível de se atingir sem a ampla utilização de tecnologia na educação. Informática e comunicações dominarão a tecnologia do futuro (D'AMBROSIO, 1996, p. 80).

É possível pensar que o futuro nessa citação é a realidade de hoje. Maltempi e Mendes (2016) afirmam que "utilizar as Tecnologias Digitais em sala de aula é ser coerente com o tempo em que vivemos" (MALTEMPI; MENDES, 2016, p.10).

É nesse contexto que os Parâmetros Curriculares Nacionais destacam o uso consciente das tecnologias com a finalidade de desenvolver no aluno a autonomia com a utilização de softwares que favoreçam pensar, refletir e criar soluções na realização de atividades, de modo que as tecnologias sejam parceiras no desenvolvimento cognitivo do aluno (BRASIL, 2002). Além disso, segundo Santos e Silva (2017) as tecnologias podem ser relevantes no processo de introdução à ciência no contexto da Educação Básica, em uma perspectiva cidadã. Segundo os autores, os professores podem suscitar discussões éticas, relacionando as tecnologias e a internet às possíveis contribuições para a prática de ensino.

Algumas ideias e iniciativas, bem como atividades investigativas com Tecnologias podem vir a suprir essa necessidade da sala de aula de Matemática na Educação Básica, se difundidas na formação inicial ou na formação continuada de professores. Em Borba, Scucuglia e Gadanidis (2014), os autores discutem pesquisas em Educação Matemática com o uso de tecnologias que surgiram e foram investigadas em determinada época, e as dividem em quatro fases. Os autores ressaltam que não se trata de fases sem conexões entre si, tampouco significa que o surgimento de uma, encerra a anterior. Pelo contrário, novos trabalhos continuam surgindo com tecnologias mais comuns numa fase, mesmo quando a próxima está se desenvolvendo. Para dissertar sobre as quatro fases, Borba, Scucuglia e Gadanidis (2014, p. 18) apresentaram "tecnologias, atividades matemáticas, perspectivas teóricas e outros aspectos que caracterizam cada uma das quatro fases".

A primeira fase, na qual se falava em tecnologias informáticas ou computacionais, foi marcada por estudos com computadores, calculadoras simples e científicas, e com o software LOGO. Foi também nessa fase que a possibilidade de implementar laboratórios de informática nas escolas começou a ser cogitada. A perspectiva teórica denominada construcionismo (PAPERT, 1980) embasava o uso pedagógico do LOGO, que por meio de comandos, determinava procedimentos para serem feitos pela tartaruga na tela do

\footnotetext{
${ }^{6}$ Entende-se Mídias como artefatos tecnológicos que possibilitam a extensão do conhecimento, a produção de conhecimento de forma distinta ao utilizar dado artefato e a moldagem recíproca entre o Ser Humano e a Mídia em um processo coletivo de produção de conhecimento (BORBA; VILLAREAL, 2005), por exemplo, é possível ter ideias diferentes ao pensar uma resolução mentalmente, ao usar lápis e papel e ao utilizar um software.
} 
computador, formando figuras geométricas. Borba e Penteado (2002) apontam que nos anos 1980, uma discussão rondava a comunidade educacional, no que diz respeito ao uso de computadores na sala de aula. Segundo os autores, os assuntos tomavam duas frentes, a que repudiava a ideia, atribuindo a opinião ao alto custo dos equipamentos, ao risco de extinção da profissão docente, e ainda à desumanização do aluno, enquanto que, a outra frente, defendia a ideia de que o uso da informática era a solução para entraves relativos à formação de professores e à aprendizagem.

No início dos anos 1990 a segunda fase já estava sendo iniciada, marcada pelo acesso e popularização dos computadores pessoais. Com essa popularização, novas tecnologias surgiram voltadas à representação gráfica de funções, como calculadoras gráficas e softwares educacionais de múltiplas representações de funções, como Derive, Winplot e Graphmatica, que permitiram explorações de funções por meio da experimentação. Além disso, softwares de Geometria Dinâmica, como o CabriGéomètre e o Geometricks, foram produzidos e permitiram que construções geométricas fossem visualizadas, dinamizadas e experimentadas.

A terceira fase teve início no final da década de 1990 com o avanço da Internet no Brasil, que começou a ser utilizada como meio de comunicação e fonte de informações. Nessa fase, o termo Tecnologias da Informação (TI) começa a dar lugar às Tecnologias de Informação e Comunicação (TIC), por conta das novas formas de comunicação que passam a ser acessíveis. Ainda nesta fase, as formas de Educação a Distância foram revistas e diversas possibilidades como e-mails, chats e fóruns passaram a ser exploradas.

Já a quarta fase, caracterizada pelo acesso rápido à Internet, vem se desenvolvendo por conta da qualidade da conexão e o constante aprimoramento das formas de comunicação online. Nessa fase, o termo Tecnologias Digitais (TD) é o que tem sido mais usado, por ser mais abrangente do que as TIC, pois além de tratar da informação e comunicação, o termo está voltado para produção de vídeos, comunicadores online com tele presença (como o Skype), ambientes virtuais de aprendizagem, aplicativos, objetos virtuais de aprendizagem, celulares inteligentes e outras tecnologias portáteis.

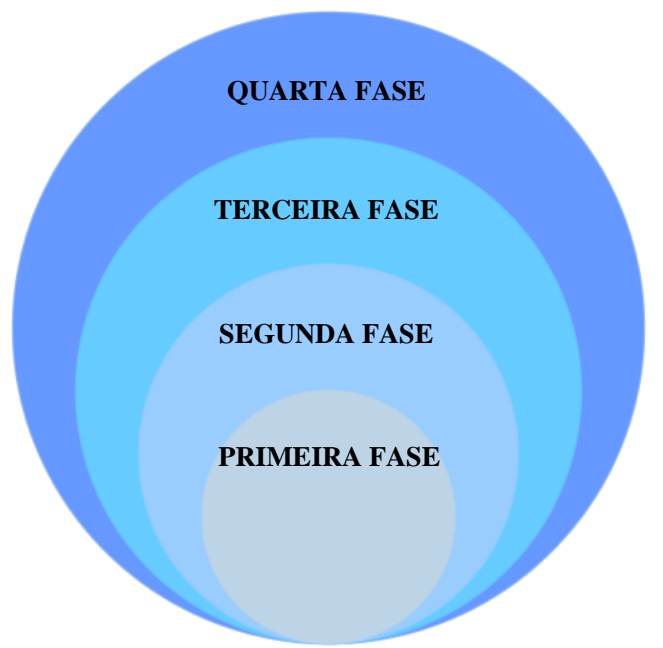

Figura 1: Integração entre as fases das Tecnologias Digitais em Educação Matemática. Adaptado de Borba, Scucuglia e Gadanidis (2014, p. 38).

Como já citado, ao iniciar uma fase, a anterior não é encerrada. O que ocorre é que outras inovações tecnológicas surgem e formam cenários de investigações distintas do que 
estava sendo anteriormente produzido. É nesse sentido que há sobreposição das fases que se integram e concebem a relação registrada no diagrama da figura 1.

Ao explicitar essas fases busca-se esclarecer que as atividades discutidas nesse artigo independentemente da fase a qual ela se iniciou, pode ser utilizada nos dias atuais na Educação Básica de acordo com a realidade de artefatos disponíveis em cada escola. Ao relatar os artefatos calculadoras, computadores e celulares inteligentes, serão apresentadas pesquisas que envolvem diferentes tipos de usos dessas tecnologias.

\section{Exploração matemática com calculadoras gráficas na Educação Básica}

Na primeira fase das Tecnologias Digitais em Educação Matemática, as discussões estavam centradas nos computadores e nas calculadoras simples e científicas. Durante essa fase poucas instituições eram equipadas com computadores para uso dos alunos, e as calculadoras científicas ainda não eram populares. Embora as calculadoras simples fossem mais acessíveis, seu uso na Educação Básica ainda era restrito, pois a este tipo de calculadora estava associada a ideia de que ela causaria dependência dos estudantes para fazer cálculos e poderia causar prejuízos ao desenvolvimento do raciocínio matemático dos alunos (SELVA, BORBA, 2010).

Desse modo, as calculadoras gráficas enfrentaram resistência para sua utilização na Educação Básica, contudo passaram a fazer parte das investigações matemáticas em sala de aula e, mais especificamente, estiveram presentes na segunda fase das Tecnologias Digitais em meados de 1990 no Brasil, como sendo uma tecnologia móvel capaz de mudar a dinâmica da sala de aula sem ter que se deslocar para laboratórios de informática (BORBA; SCUCUGLIA; GADANIDS, 2014).

Várias pesquisas foram desenvolvidas nessa época em diferentes níveis de ensino, porém as atividades, por envolver questões gráficas de funções, podem ser adaptadas ao ensino fundamental, médio e superior. Devido às dificuldades de elaborar atividades e divulga-las nessa época, este artigo foca especificamente em pesquisas do Brasil relacionadas ao grupo de pesquisa GPIMEM, porém pode-se encontrar levantamentos de outras pesquisas no Brasil, bem como em outros países e em livros como Borba (1999).

O uso de calculadoras no GPIMEM se iniciou em 1992 e permitiu desenvolver e aplicar atividades de ensino na disciplina de Matemática Aplicada para o curso de ciências biológicas da UNESP de Rio Claro (DOMINGUES; HEITMANN; SOBRINHO, 2013). A partir de então, no grupo de pesquisa surgiram teses e dissertações vinculadas ao uso de calculadoras, tais como Gracias (1996) com o título "calculadoras gráficas uma proposta didático-pedagógica para o tema funções quadráticas", na qual a autora buscou investigar o potencial das calculadoras gráficas no processo de ensino-aprendizagem de matemática.

Junto às calculadoras gráficas havia sensores que permitiam discutir gráficos relacionados ao deslocamento, movimento e velocidade, que culminaram em pesquisas como Scheffer (2001), Bonafini (2004) e Scucuglia (2006).

Scheffer (2001) com o título "Sensores, Informática e o Corpo: a noção de movimento no Ensino Fundamental", em que a autora investigou a representação gráfica cartesiana de movimentos corporais por meio da calculadora gráfica junto ao CBR (Calculator Based Ranger) que consiste em um sensor ultrassônico de movimento que pode ser ligado à 
calculadora permitindo obter gráficos e tabelas de posição por tempo. Bonafini (2004) cujo título é "Explorando conexões entre a Matemática e a Física com o uso da calculadora gráfica e CBL", em que o autor realizou Experimentos de Ensino com alunos do Ensino Superior de modo a investigar relações de tópicos como expressões, equações diferenciais, ajustes de curvas, dentre outros. O CBL - Calculator Based Laboratory - é um acessório que permite registrar variações como temperatura no tempo, tensão elétrica, intensidade luminosa, gerando gráficos e tabelas diretamente na calculadora. Já na dissertação de Scucuglia (2006), intitulada "A Investigação do Teorema Fundamental do Cálculo com calculadoras gráficas", o autor realizou experimentos de ensino com alunos da graduação em Matemática da UNESP de modo a verificar as influências da calculadora em conceitos como Soma de Riemann, Integração e Teorema Fundamental do Cálculo.

Nessa temática, em 1999 foi publicado o livro "Calculadoras Gráficas e Educação Matemática" (BORBA, 1999) que foi fruto de um curso desenvolvido junto a professores do Ensino Fundamental, Médio e Superior com questões teóricas e práticas. Segundo Borba (1999, p.18):

As calculadoras gráficas podem ser vistas como computadores munidos de alguns aplicativos e que (ainda) não têm capacidades de comunicação (Internet, fax, etc..). Dizemos que elas podem ser vistas como os computadores na medida em que, para fins educacionais, geram gráficos da mesma forma que os softwares usuais, operam com matrizes, fazem ajustes estatísticos e geram gráficos correspondentes. Podem, também, de forma semelhante aos computadores, dispensar os estudantes de lidar com cálculos tediosos e de, ponto a ponto, gerar um gráfico no papel. Muitas calculadoras gráficas já possuem tabelas, sendo possível remeter um conjunto de pontos para a janela gráfica, assim como enviar pontos selecionados de um dado gráfico para essas tabelas, abrindo uma importante trilha para a investigação matemática na sala de aula.

A partir da citação, é notável a utilidade das calculadoras gráficas na sala de aula de Matemática, pois para se trabalhar com computadores podem emergir problemas nos laboratórios, falta de computadores, instalações elétricas e mobílias diferenciadas (CHINELLATO, 2014; FARIA et al., 2016). Ressalta-se ainda as potencialidades das calculadoras gráficas no quesito ganho de tempo para se desenhar funções e criar conjecturas por meio da análise de aspectos visuais. É nesse sentido que em Borba (1999) são encontradas várias ideias de atividades que podem ser desenvolvidas na Educação Básica como no estudo de funções e ideias para se trabalhar com matrizes, determinantes e sistemas lineares.

Com relação ao estudo de funções desenvolveu-se atividades acerca da investigação dos coeficientes " $a$ ", " $b$ " e " $c$ " da função $y=a x^{2}+b x+c$. Na atividade, plotava-se várias funções nas calculadoras para investigar de que forma as mudanças nesses coeficientes alteravam o formato dos gráficos nos quesitos concavidade, deslocamento entre os eixos e ponto do vértice. Trabalhava-se com grupos que discutiam conjecturas, realizavam relatórios escritos para uma posterior discussão da turma onde cada grupo apontava suas descobertas, como pode ser visto na figura 2, em que a imagem da esquerda representa a família de parábolas $y=x^{2}, y=2 x^{2}$ e $y=4 x^{2}$ usada para sustentar a conjectura de um grupo. Já a imagem da direita, consiste no conjunto de parábolas (A) $y=x^{2}-3 x+2$, (B) 
$y=2 x^{2}-3 x+2$, e (C) $y=3 x^{2}-3 x+2$, que sustentou $\mathrm{O}$ argumento de um aluno durante as explicações da aula.
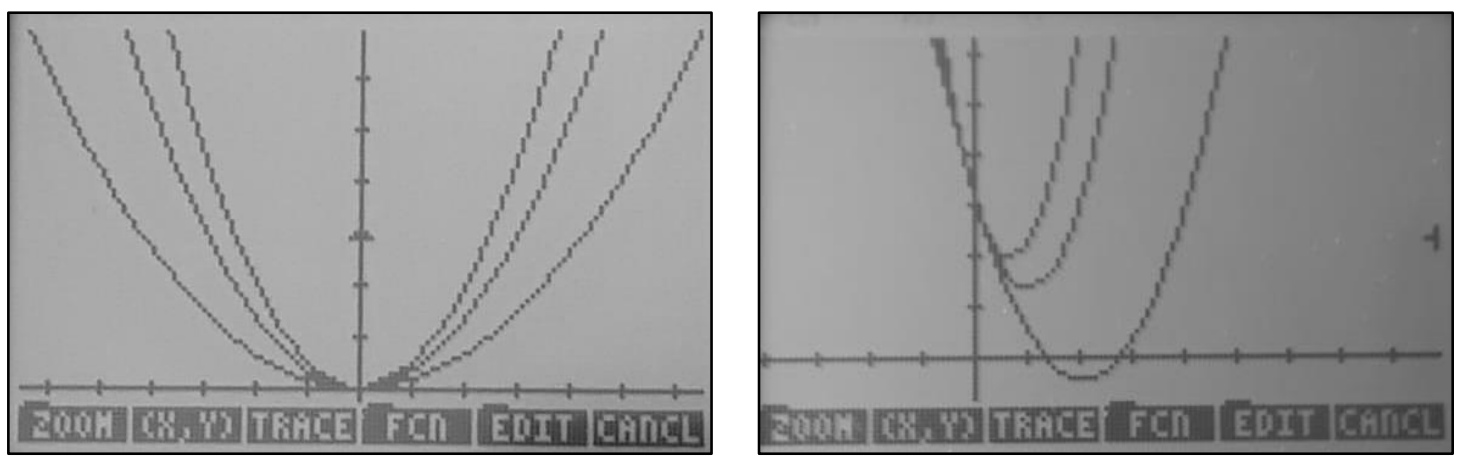

Figura 2: Imagens dos gráficos plotados na calculadora gráfica. Adaptado de Borba (1999, p. 27).

As calculadoras favoreceram várias explorações matemáticas, porém ela rapidamente foi ultrapassada frente aos computadores portáteis. Por mais que esse processo tenha demandado tempo de evolução, a falta de políticas públicas e o alto valor para se comprar essas calculadoras se comparado aos computadores e notebooks fez com que elas acabassem caindo em desuso no Brasil, mesmo frente aos problemas de infraestrutura dos laboratórios de informática (BORBA, SCUCUGLIA; GADANIDS, 2014).

Ressalta-se ainda que as mesmas atividades podem ser adaptadas para outras plataformas, softwares ou aplicativos, com novas possibilidades de interação (BORBA, 2002), conforme será apresentado nas próximas seções.

\section{Os computadores e os softwares matemáticos na Educação Básica}

A terceira fase, que ganhou força na década de 2000, é relacionada à exploração matemática com softwares em computadores. Dentre os softwares que se destacaram nesse tempo, estão: CabriGéomètre, Régua e Compasso, Winplot, Graphmatica e GeoGebra, sendo que este último vem ganhando destaque na área de Educação Matemática, por estar sempre sendo atualizado e por permitir aos usuários compreender, analisar e tirar suas próprias conclusões a respeito ao que está sendo observado na tela (URDANETA; GONZALEZ; CASTILLO, 2017).

O GeoGebra permite que construções sejam representadas de forma aritmética, algébrica e geométrica, concomitantemente (FARIA, 2016) e, atualmente, está disponível para construções tridimensionais, é compatível com multiplataformas, possui acesso livre e pode ser explorado no computador, no tablet e no celular. Ademais, o GeoGebra possui um canal próprio chamado GeoGebra Tube ${ }^{7}$, onde é possível disponibilizar e baixar construções, vídeos e materiais, e ainda o GeoGebra Book, onde é possível criar e compartilhar uma coleção de materiais próprios do usuário com folhas de trabalho que permitem a organização de Applets, materiais favoritos, livros online dinâmicos e interativos para ensino e para aprendizagem.

\footnotetext{
${ }^{7}$ http://www.geogebratube.org
} 
O GeoGebra fez parte de dissertações e teses do GPIMEM (ANDRADE, 2017; BARROS, 2013; CHINELLATO, 2014; FARIA, 2012; FARIA, 2016; MAZZI, 2014; SOUTO, 2013; BRAGA, 2016). Algumas dessas pesquisas tiveram atividades voltadas especificamente para a Educação Básica, como Faria (2012), Barros (2013) e Faria (2016). Na primeira, Faria (2012) analisou as contribuições que a exploração de Padrões Fractais por alunos do Ensino Médio no GeoGebra, traziam ao Processo de Generalização de Conteúdos Matemáticos. Foram realizadas seis atividades de manipulação e análise dos Padrões Fractais Árvore Pitagórica, Triângulo de Sierpinski, Curva de Koch, Tetra Círculo, Lunda-Design e Hexagonal tipo Dürer (Figura 3).

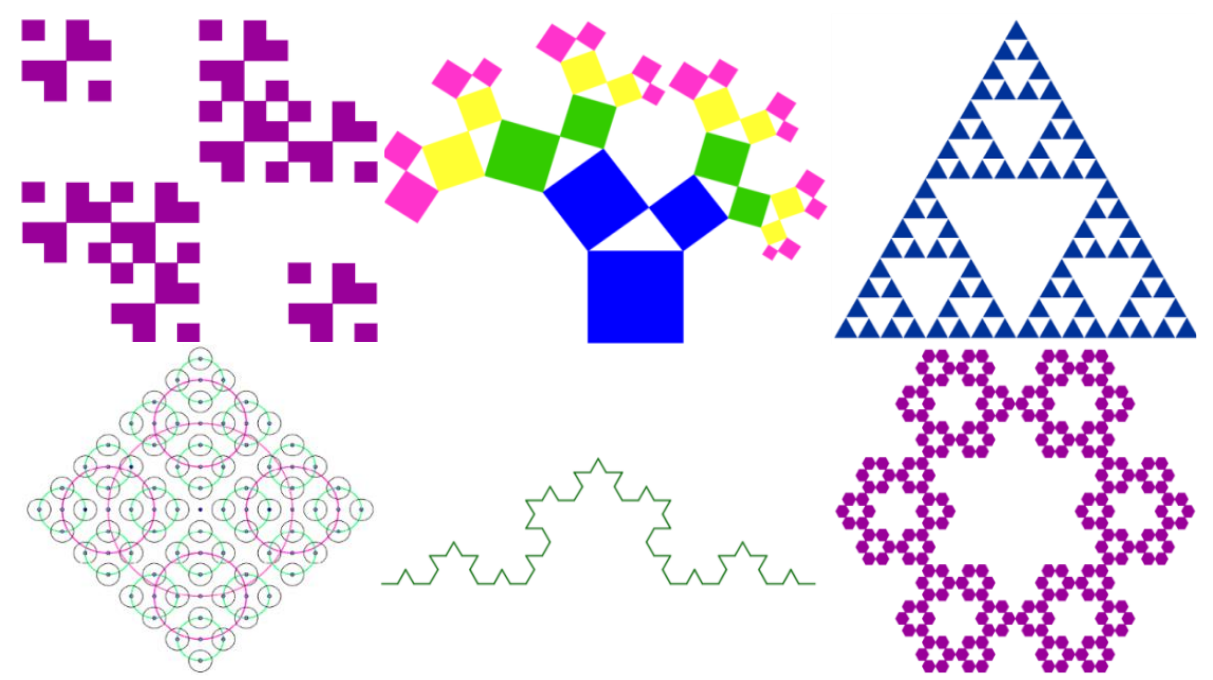

Figura 3: Padrões Fractais construídos no GeoGebra: Lunda-Design, Árvore Pitagórica, Triângulo de Sierpinski, Tetra Círculo, Curva de Koch, e Hexagonal tipo Dürer, nessa ordem. (FARIA, 2012)

Todas as atividades foram desenvolvidas no software GeoGebra. Os resultados obtidos na pesquisa indicaram que "o trabalho com Padrões Fractais contribui com o processo de generalização de conteúdos matemáticos por possuírem características que possibilitam a exploração de diversos conteúdos matemáticos" (FARIA, 2012, p. 6). As propriedades dos fractais autossimilaridade e a complexidade infinita contribuíram para que, a partir da análise de alguns níveis, fossem pensados casos gerais. Para tanto, o GeoGebra possibilitou a visualização, construção e manipulação dos fractais, colaborando para a "percepção das particularidades que fazem com que o Padrão Fractal repita infinitamente, ao longo das iterações, sua estrutura inicial" (FARIA, 2012, p. 6).

Já na pesquisa de Barros (2013), foi criado "um ambiente denominado micromundo composto por applets do software GeoGebra e vídeos da coleção $\mathrm{M}^{3}$ Matemática Multimídia $^{8 "}$ (BARROS, 2013, p. 13). Mais precisamente, foram analisadas as condições criadas pelo micromundo na aprendizagem matemática de alunos do Ensino Médio mediado por uma professora. Barros (2013), baseando-se no Construcionismo e na Teoria Cognitiva de Aprendizagem Multimídia, constatou que as dimensões construcionistas contribuíram para o engajamento e interesse dos alunos em realizar as tarefas, e nesse

\footnotetext{
${ }^{8} \mathrm{O} \mathrm{M}^{3}$ é uma página que contém recursos educacionais de Matemática multimídia em formatos digitais Desenvolvido pela Unicamp com financiamento do FNDE, SED, MCT e MEC para o Ensino Médio de Matemática no Brasil (BARROS, 2013, p. 2). Disponível em: http://m3.ime.unicamp.br/. Acesso: 31/05/2017.
} 
sentido, a exploração do micromundo possibilitou que os alunos estabelecessem conexões entre as multimídias, mesmo tendo optado por caminhos distintos durante o processo de compreensão do conceito de volume de uma pirâmide. Ademais, por se tratar de um ambiente exploratório e interativo os alunos puderam visualizar e interpretar as figuras geométricas espaciais de diferentes formas. Diante da análise dos dados a autora observou indícios de aprendizagem.

Nas atividades desenvolvidas em Faria (2016) o intuito foi de que os recursos do GeoGebra fossem utilizados de forma intradisciplinar, com base em assuntos inerentes ao Raciocínio Proporcional. Embora o foco seja nos anos finais do Ensino Fundamental, as atividades podem ser realizadas com as mais diversas séries, a critério do professor, pois trata-se de uma temática ampla e relevante para toda a Educação Básica e para as mais diversas situações do cotidiano. Após a publicação da tese, a autora desenvolveu, em conjunto com o aluno de iniciação científica Franço Willy de Souza Nascimento, sob sua orientação na Universidade Federal do Pará, o GeoGebra Book" "Desenvolvendo e Explorando o Raciocínio Proporcional" (Figura 4). Nesse GeoGebra Book foram disponibilizadas as atividades, construções e roteiros desenvolvidos em Faria (2016).

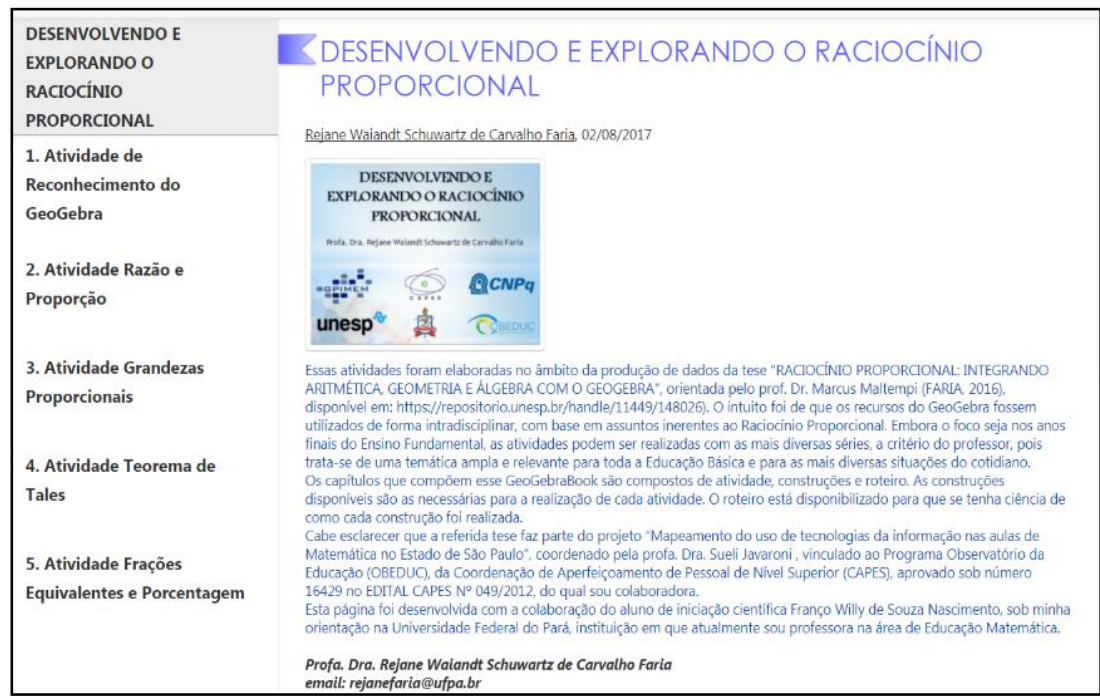

Figura 4: Interface do GeoGebra Book Desenvolvendo e Explorando o Raciocínio Proporcional. Fonte: https://www.geogebra.org/m/MHSqp4xU.

No que tange ao uso de computadores e GeoGebra, é notável suas potencialidades ao reescrever atividades desenvolvidas nas calculadoras gráficas de uma maneira mais dinâmica e com uma plataforma mais amigável. Por exemplo, é possível refazer o gráfico da figura 2 (lado direito) colocando cada função com uma cor diferente e ainda, fazer uma função pela sua forma geral $\left(y=a x^{2}+b x+c\right)$ de modo que, por meio da opção "controle deslizante" do software, é possível animar ou arrastar o parâmetro " $a$ " e verificar o comportamento da função em tempo real de acordo com a variação, que perpassa números decimais dificilmente testado por alunos. Além disso, o GeoGebra permite que fique representado algebricamente (na Janela de Álgebra) e geometricamente (na Janela de Visualização) essas variações dos parâmetros, como é possível observar na figura 5, na qual o controle deslizante do parâmetro " $a$ " está variando de -5 a 5, e " $a$ " apresenta o valor 4,9.

\footnotetext{
${ }^{9}$ https://www.geogebra.org/material/show/id/454389
} 


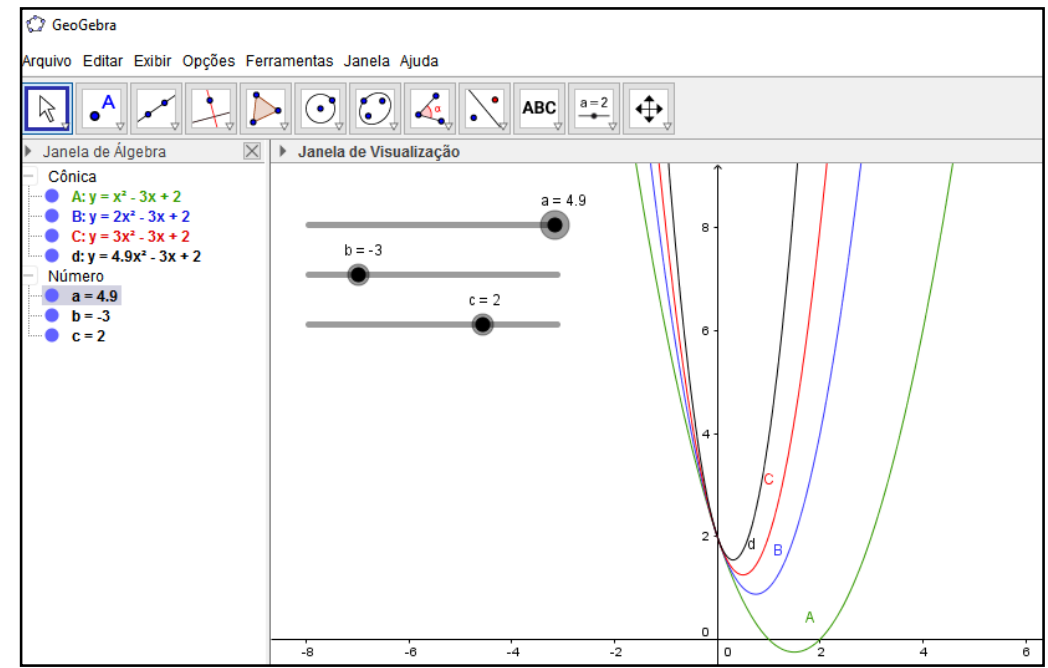

Figura 5: Reconstrução da figura 2 com o software GeoGebra.

Assim como as investigações citadas, outras pesquisas propuseram e ainda tem proposto a Exploração Matemática com softwares educacionais na Educação Básica, com objetivos direcionados na construção do conhecimento dos alunos por meio de atividades, nas potencialidades e limitações dos softwares matemáticos educacionais e sobre questões que perpassam a elaboração e realização de aulas com tais tecnologias. Além disso, algumas pesquisas mostram o interesse dos professores em utilizar computadores em sala de aula, ressaltando potencialidades de seu uso em diferentes conceitos de matemática. Em contrapartida, algumas pesquisas apontam também a falta de formação, seja ela inicial ou continuada.

Dentre essas pesquisas, as desenvolvidas no âmbito do projeto intitulado "Mapeamento do uso de tecnologias da informação nas aulas de Matemática no Estado de São Paulo"10 do GPIMEM, por exemplo, atuaram com o intuito de mapear o uso de tecnologias presentes nas aulas de Matemática na rede estadual de São Paulo e fornecer cursos de extensão para que esses professores possam pensar na inclusão dos recursos das tecnologias informáticas em suas aulas (FARIA et al., 2016).

Tais pesquisas (CHINELLATO, 2014; PERALTA, 2015; OLIVEIRA, 2014) mostraram que as escolas que integram diferentes diretorias regionais de ensino da rede estadual de Educação de São Paulo não oferecem uma estrutura adequada de equipamentos em seus laboratórios. Além disso, muitos professores mostraram interesse em utilizar computadores em sala de aula ressaltando potencialidades de seu uso em diferentes conceitos de matemática, no entanto, a maior parte deles declarou não se sentir apto para realizar atividades de matemática com suas turmas usando softwares matemáticos devido a carências relacionadas a formação inicial e a rápida evolução das tecnologias. Buscando atuar nessa formação quanto à relação das tecnologias na atuação docente dessa área, diversas pesquisas foram desenvolvidas cuja produção de dados se deu por meio de cursos que buscaram a formação continuada desses professores integrando atividades matemáticas e tecnologias (ZAMPIERI; JAVARONI, 2014; FARIA, 2016; BRAGA, 2016).

\footnotetext{
${ }^{10}$ Projeto vinculado ao Programa Observatório da Educação (OBEDUC), da Coordenação de Aperfeiçoamento de Pessoal de Nível Superior (CAPES), aprovado no EDITAL CAPES No 049/2012.
} 
Nota-se a intensa utilização de modo produtivo de softwares e computadores em sala de aula, em que professores visam construir conceitos com o auxílio destas mídias. Porém têm-se indicativos na literatura de que, assim como ocorreu com as calculadoras, essa mídia encontra problemas para efetiva aplicação em sala de aula e, possivelmente, pode ser substituída por outros artefatos. A maior facilidade de transporte e de compra de outras tecnologias tem cedido lugar para discussões sobre a exploração matemática com tablets e celulares, visto que já estão presentes em boa parte das salas de aula, como será discutido na próxima seção (BORBA; SCUCUGLIA; GADANIDS, 2014; ROMANELLO, 2016).

\section{A atual fase e os possíveis próximos passos das TD na exploração matemática}

Em meio aos cenários apresentados nas seções anteriores, observa-se que as pesquisas envolvendo o uso de Tecnologias Digitais no ensino de Matemática, diferem de acordo com as possibilidades que novas interfaces apresentam. O celular, que atualmente é um dispositivo móvel com grande popularidade e que está inserido na última fase das Tecnologias Digitais, também vem ganhando espaço nesse cenário. Isso porque, além da evolução da tecnologia e do avanço constante desses dispositivos, alguns entraves que podem ser encontrados com o uso dos computadores, por exemplo, não são encontrados para o uso do celular.

Pesquisas como, Paulo e Firme (2014) e Silva, Medeiros e Morelatti (2014) apontam que os laboratórios de informática das escolas não estão sendo utilizado pelos professores, ou porque há a falta de manutenção dos laboratórios, ou pelo fato dos professores não saberem utilizar os recursos que são oferecidos. É preciso considerar o fato de ter que deslocar os alunos da sala de aula para o laboratório, fazendo com que o tempo da aula seja ainda menor, além dos alunos terem que trabalhar na disposição das carteiras oferecidas pelo laboratório.

Nesse sentido, Borba e Lacerda (2015) apontam que as pesquisas em Educação Matemática tendem a ser realizadas na perspectiva de um celular por aluno, no sentido de que trabalhar com os alunos com um equipamento que lhes é familiar, sem precisar sair da sala de aula, ligar equipamentos e resolver tantas outras questões técnicas, pode tornar o andamento da aula mais ágil e eficaz.

Pensando na questão da mobilidade do celular, emergem questionamentos como: por que não utilizar as calculadoras gráficas? Afinal, também permitem o trabalho na própria sala de aula. Uma resposta possível é a de que, hoje em dia, elas não têm a mesma popularidade do celular. Dessa forma seria necessário fornecer calculadoras aos alunos ou sugerir que eles as adquirissem. Entretanto, atualmente, os celulares são como microcomputadores que permitem criar, editar e enviar arquivos dos mais diversos formatos, além de permitirem o acesso de aplicativos diversos, alguns deles, fornecendo as mesmas funcionalidades das calculadoras gráficas em um formato mais atrativo. Tais recursos tornam a quarta fase "um cenário fértil ao desenvolvimento de investigação e à realização de pesquisas" (BORBA; SCUCUGLIA; GADANIDIS, 2014, p.37), pois permite maior interatividade, proporcionando diversas opções para trabalhar atividades matemáticas em sala de aula. 
Além disso, nos dias de hoje, a maior parte dos alunos que frequentam as escolas no Brasil possuem acesso ao celular inteligente (IBGE, 2015), e estão levando esses dispositivos para o meio escolar. Tais dispositivos estão adentrando nas salas de aula de tal forma que, em 2008, o governo do estado de São Paulo criou um decreto no qual fica "proibido, durante o horário das aulas, o uso de telefone celular por alunos das escolas do sistema estadual de ensino"11. No entanto, no ano seguinte, foi publicado um documento sobre normas gerais de conduta escolar trazendo uma abertura, desconhecida pela maioria dos professores, permitindo o uso dos celulares na sala de aula desde que essa utilização não perturbe o ambiente escolar e prejudique o aprendizado ${ }^{12}$. No final de 2017, entrou em vigor a alteração da lei que proibia o uso do celular, passando a permitir a utilização do dispositivo em atividades pedagógicas e orientada por educadores.

Buscando apresentar algumas pesquisas envolvendo o celular como um recurso mediador no ensino, percebe-se que essa temática ainda é pouco explorada dentro e fora do GPIMEM. Foram encontradas poucas pesquisas envolvendo o uso dos celulares em sala de aula, principalmente voltadas para o ensino de Matemática na Educação Básica (DOMINGUES, 2016; LADEIRA, 2015; NASCIMENTO, 2014; ROMANELLO, 2016).

Ladeira (2015) traz sua análise sobre as possibilidades didático-pedagógicas dos celulares, abordando o conceito de função do primeiro grau para alunos do primeiro ano do Ensino Médio, com uma abordagem de ensino inovadora. Durante as atividades realizadas pela pesquisadora, os alunos utilizaram a internet, a câmera do celular para fotografar e gravar vídeos e também utilizaram a calculadora para auxiliar na resolução das atividades. Por fim, a pesquisadora afirma que é "fundamental conhecer e avaliar o potencial da aprendizagem móvel e identificar as novas maneiras em que a mobilidade pode contribuir para as experiências significativas de aprendizagem" (LADEIRA, 2015, p.217). Além disso, ela enfatiza que a utilização desse dispositivo não se limita a utilização de fórmulas, mas permite a análise das situações-problemas propostas, possibilita a representação e principalmente a visualização, além da comunicação entre os alunos, favorecendo o raciocínio.

Nascimento (2014) também fez uso de aplicativo para trabalhar os conceitos de função. Para isso, o pesquisador, em colaboração com mais sete professores do Colégio Flama, desenvolveu o aplicativo "Funcionalidade". Esse aplicativo cria cenários de aprendizagem diferenciados, podendo vir a reestruturar novas práticas pedagógicas de modo a potencializar o ensino (NASCIMENTO, 2014). Após diversas discussões e ajustes no aplicativo, ele foi apresentado para alunos do primeiro ano do Ensino Médio, do Sistema Flama de Ensino, situado na cidade Duque de Caxias - RJ. A maior parte dos alunos, comparando com o modo como aprenderam função, caracterizou o aplicativo como sendo melhor que os livros por proporcionar maior interação. Com relação aos professores, Nascimento (2014) destaca a resistência deles frente às Tecnologias Digitais, afirmando que "não pode[m] continuar fechando a porta para a inovação, deve[m] sim, assumir o papel de mediador e coautor da informação junto aos seus alunos" (NASCIMENTO, 2014, p. 97).

Romanello (2016), assim como Ladeira (2015) e Nascimento (2014), explorou o conceito de função em uma turma do nono ano do Ensino Fundamental utilizando o aplicativo

\footnotetext{
${ }^{11}$ http://www.al.sp.gov.br/repositorio/legislacao/decreto/2008/decreto\%20n.52.625,\%20 de\%2015. 01.2008.htm).

12 http://www.educacao.sp.gov.br/spec/wp-content/uploads/2013/09/normas_gerais_condu ta_web1.pdf.
} 
Matemática. A opção pelo nono ano se deu pelo fato de ser quando os alunos têm um primeiro contato com o conteúdo função e que, no Ensino Médio, será mais aprofundado. A pesquisadora apresenta como proposta a exploração de gráficos pelos alunos de modo a sistematizar o conceito de função e, também, trabalhar com as propriedades dos gráficos de função do primeiro grau e função quadrática, discutindo como cada parâmetro das funções interfere no comportamento do gráfico (figura 6). Para essa exploração foram realizadas quatro atividades que levaram os alunos a discutirem assuntos além do previsto como: máximo, mínimo e vértice de função quadrática; encontrar a equação de uma reta a partir de dois pontos; e gráficos de funções de grau maior que três, que são temas trabalhados no Ensino Médio. Sendo assim, a autora aponta que a atividade poderia ser também trabalhada com alunos do Ensino Médio, pois é quando esses conceitos são explorados de forma mais detalhada, podendo o aplicativo Matemática auxiliar no processo de formalização de conceitos devido à manipulação e visualização.

Na figura abaixo, é possível verificar a interface do aplicativo Matemática presente na pesquisa de Romanello (2016). Nota-se que a interface do aplicativo de celular difere das calculadoras gráficas e do computador com GeoGebra, anteriormente apresentadas, mas em termos de discussões do conteúdo de funções é possível fazer investigações similares, com o diferencial do Touch Screen, que vem sendo investigado em pesquisas como Bairral et al. (2015), e as "cores" de cada gráfico se pensarmos no caso das calculadoras gráficas.

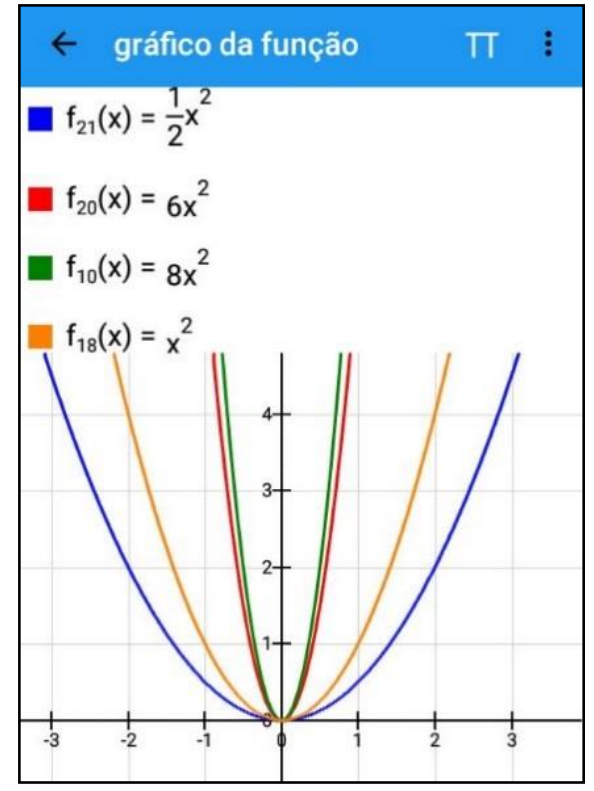

Figura 6: Variação do parâmetro " $a$ " na interface do aplicativo Matemática (ROMANELLO, 2016).

Domingues (2016) apresentou uma atividade realizada para investigar as propriedades do determinante de matrizes por meio do aplicativo MathHelper. Tal atividade foi aplicada com uma turma do segundo ano do Ensino Médio, na qual os alunos testavam diferentes variações de matrizes e analisavam o resultado de suas determinantes, para tentar sistematizar propriedades dos determinantes de matrizes. As atividades permitiram que fossem testadas inúmeras matrizes, o que em uma aula tradicional, dispondo apenas de lápis e papel, não poderia ter sido feito, devido à questão de tempo. Na maioria das vezes, esse conteúdo acaba sendo trabalhado passando um único exemplo de cada propriedade 
de determinante. Enquanto que, com essa atividade foi possível que os alunos desenvolvessem as propriedades por meio da exploração de diversas matrizes.

Por fim, Ribas, Silva e Galvão (2012) ressaltam "a necessidade e importância do desenvolvimento de novas pesquisas sobre a utilização de um telefone celular como recurso didático instrucional para mediar práticas de ensino" (RIBAS; SILVA; GALVÃO, 2012, p.10), de modo a investigar as potencialidades desse recurso no espaço educativo. Afinal, "Não importa a professores e alunos apenas aprender a usar os novos meios tecnológicos na Educação; importa muito mais pensar as tecnologias para a Educação" (AXT, 2002, p. 38).

Dessa forma, deve haver uma conscientização dos professores e dos alunos quanto ao uso dos celulares inteligentes nas salas de aula de Matemática, de modo que o dispositivo seja visto como um artefato que possibilite a construção do conhecimento. Mais do que a importância dada aos recursos utilizados, como vídeos, fotos, gravações, softwares, calculadoras ou aplicativos, deve-se dar importância à metodologia adotada pelo professor junto a determinada tecnologia de forma a favorecer a aprendizagem (BORBA, 2001).

\section{Considerações finais}

Utilizar Tecnologias Digitais em sala de aula de Matemática é quase que uma necessidade nos dias atuais devido as cobranças dos alunos, da escola ou mesmo da necessidade de inovação do professor em suas aulas. Mesmo assim, nota-se algumas barreiras para efetiva implementação dessas tecnologias nas aulas.

Como entraves destacam-se estrutura curricular não flexível, falta de preparo dos professores e falta de infraestrutura das escolas. O preparo do professor pode estar aliado a sua formação inicial ou continuada, o que pode acarretar em dificuldades em elaborar atividades matemáticas com tecnologias. Alguns professores, tem receio em sair da zona de conforto, em que dominam o conteúdo e anteveem o andamento das aulas, para se arriscar em uma zona de risco, onde imprevistos e questões conflitantes podem emergir.

Este artigo destacou o fato de as tecnologias sofrerem alterações de acordo com sua Fase que está relacionada a uma ordem cronológica. Atividades que antes eram realizadas com mais desenvoltura em calculadoras gráficas, ganharam mais funções para serem realizadas em softwares computacionais, e mais versatilidade em aplicativos de celulares.

Sendo assim, discutiu-se a necessidade de se ter certo cuidado para adaptar determinada atividade a uma tecnologia mais recente, ou mesmo, ao se criar uma nova atividade. Desse modo, é fundamental que o professor se atente ao ganho qualitativo que essa nova mídia permite em termos de interação e reflexão, se comparado às mídias anteriores, assim como foi apresentado o exemplo da investigação do tema de "funções" nos artefatos calculadora gráfica, computador e celular inteligente.

Entende-se que mesmo não sendo um processo fácil o professor deve buscar meios para aproximar a sala de aula da realidade tecnológica vivenciada pelos alunos, e ainda, deve aproveitar o cenário e os artefatos que a escola e os alunos disponibilizam para realizar explorações e atividades investigativas que favoreçam a realização de conjecturas, teste de hipóteses e tomada de decisões, de modo a produzir conhecimento matemático em sala de aula e formar cidadãos críticos e criativos. 


\section{Apoio}

O presente trabalho foi realizado com apoio da Coordenação de Aperfeiçoamento de Pessoal de Nível Superior - Brasil (CAPES) - Código de Financiamento 001 e com o apoio do Conselho Nacional de Desenvolvimento Científico e Tecnológico - CNPq.

\section{Referências}

ANDRADE, P. F. A sala de aula de Matemática: Influências de um curso de formação continuada sobre o uso do GeoGebra articulado com atividades matemáticas. 2017. Dissertação (Mestrado em Educação Matemática) - Universidade Estadual Paulista, Rio Claro, 2017.

AXT, M. A Escola frente às tecnologias - pensando a concepção ético-política. Caderno Temático SMED: Multimeios e Informática Educativa, Porto Alegre, p. 35-41, 2002.

BAIRRAL, M. A.; ASSIS, A. R.; SILVA, B. C. C. C. Toques para ampliar interações e manipulações touchscreen na aprendizagem em geometria. In: Seminário Internacional de Pesquisa em Educação Matemática, VI, 2015, Pirenópolis. Anais... Goiás: UEG, 2015.

BARROS, A. P. R. M. Contribuições de um Micromundo composto por recursos do GeoGebra e da Coleção $M^{3}$ para a aprendizagem do conceito de Volume de Pirâmide. 2013. Dissertação (Mestrado em Ensino de Ciências e Matemática) - Universidade Estadual de Campinas, Campinas, 2013.

BONAFINI, F. C. Explorando conexões entre a matemática e a física com o uso da calculadora gráfica e do CBL. 2004. Dissertação (Mestrado em Educação Matemática) Universidade Estadual Paulista, Rio Claro, 2004.

BORBA, M. C. Coletivos seres-humanos-com-mídias e a produção matemática. In: Simpósio Brasileiro de Psicologia da Educação Matemática, 2002, Curitiba. Anais... Curitiba: SBPEM, SBEM, 2002. p. 135-146.

BORBA, M. C. Calculadoras Gráficas e Educação Matemática. In: Série Reflexão em Educação matemática. Orgs.:FAINGUELERNT, E. K.; GOTTILIEB, F. C. Rio de Janeiro / MEM / USU: Editora Art Bureau, 1999.

BORBA, M. C.; LACERDA, H. D. G. Políticas Públicas e Tecnologias Digitais: Um Celular por Aluno. In: Educação Matemática e Pesquisa, São Paulo, v.17, n.3, p.490-507, 2015.

BORBA, M. C.; PENTEADO, M. G. Informática e Educação Matemática. 1. ed. Belo Horizonte: Autêntica, 2001.

BORBA, M. C.; PENTEADO, M. G. Pesquisas em Informática e Educação Matemática. In: Educação em Revista, no 36, p. 239-253. Belo Horizonte: 2002.

BORBA, M. C.; SCUCUGLIA, R. R. S.; GADANIDIS, G. Fases das Tecnologias Digitais em Educação Matemática: sala de aula e internet em movimento. 1.ed. Belo Horizonte: Autêntica, 2014.

BORBA, M. C.; VILLARREAL, M. E. Humans-With-Media and the Reorganization of Mathematical Thinking: information and communication technologies, modeling, experimentation and visualization. v. 39, New York: Springer, 2005. 
BRAGA, L. S. Tecnologias Digitais na Educação Básica: Um retrato de aspectos Evidenciados por Professores de Matemática em Formação Continuada. 2016. Dissertação (Mestrado em Educação Matemática) Universidade Estadual Paulista, Rio Claro, 2016.

BRASIL. Ciências da Natureza, Matemática e suas Tecnologias: Orientações Educacionais Complementares aos Parâmetros Curriculares Nacionais. v. 1. Brasília-DF: Ministério da Educação e do Desporto, 2002.

CHINELLATO, T. G. O uso do computador em escolas públicas estaduais da cidade de Limeira/SP. 2014. Dissertação (Mestrado em Educação Matemática) Universidade Estadual Paulista, Rio Claro, 2014.

D’AMBROSIO, U. Educação Matemática: Da teoria à prática. Campinas: Papirus, 1996.

DOMINGUES, N. S. Investigando as propriedades dos determinantes de matrizes com uso de celulares inteligentes. In: Congresso internacional TIC e Educação, IV...Lisboa. Anais...Lisboa: ticEDUCA, 2016.

DOMINGUES, N. S.; HEITMANN, F. P.; SOBRINHO, G. A. L. Vivências e pesquisas: compondo uma história das tecnologias em 20 anos de GPIMEM. In: BORBA, M. C.; CHIARI, A. S. S. Tecnologias Digitais e Educação Matemática. São Paulo: Livraria da Física, p.113-139, 2013.

FARIA, R. W. S. C. RACIOCÍNIO PROPORCIONAL: Integrando Aritmética, Geometria e Álgebra com o GeoGebra. 2016. Tese (Doutorado em Educação Matemática) - Universidade Estadual Paulista, Rio Claro, 2016.

FARIA, R. W. S. C.; JAVARONI, S. L. ; MALTEMPI, M. V.; CHINELLATO, T. G.; FONTANA, C. E. A. G.; SILVA, F. F. Relato de um curso desenvolvido com professores de Matemática atuantes do sexto ao nono do Ensino Fundamental. In. III Congresso Nacional de Formação de Professores (CNFP) e XIII Congresso Estadual Paulista sobre Formação de Educadores (CEPFE). Anais...Águas de Lindóia, 2016.

FARIA, R. W. S. Padrões Fractais: Contribuições ao Processo de Generalização de Conteúdos Matemáticos. 2012. Dissertação (Mestrado em Educação Matemática) - Universidade Estadual Paulista, Rio Claro - SP, 2012.

GRACIAS, T. A. S. Calculadoras Gráficas: uma proposta didático-pedagógica para o tema funções quadráticas. 1996. Dissertação (Mestrado em Educação Matemática) -Universidade Estadual Paulista, Rio Claro, 1996.

IBGE. Pesquisa Nacional por Amostras de Domicílio: Acesso à Internet e à Televisão e Posse de Telefone Móvel Celular para Uso Pessoal em 2013. Rio de Janeiro: IBGE, 2015.

KENSKI, V. M. Tecnologias e tempo docente. Campinas: Papirus, 2013.

LADEIRA, V. P. O Ensino de Funções em um Ambiente Tecnológico: uma investigação qualitativa baseada na teoria fundamentada sobre a utilização de dispositivos móveis em sala de aula como instrumentos. 2015. Dissertação (Mestrado em Ensino Matemática) Universidade Federal de Ouro Preto, Outro Preto, 2015.

MALTEMPI, M. V.; MENDES, R. O. Tecnologias Digitais na Sala de Aula: Por que não? In: IV CONGRESSO INTERNACIONAL DE TIC NA EDUCAÇÃO, 2016, Lisboa/Portugal. Anais... Lisboa/Portugal: [s.n.], 2016. 
MAZZI, L. C. Experimentação-com-GeoGebra: revisitando alguns conceitos da Análise Real. 2014. Dissertação (Mestrado em Educação Matemática) - Universidade Estadual Paulista, Rio Claro, 2014.

NASCIMENTO, H. J. Construção do conceito de função matemática: um estudo colaborativo sobre a concepção e uso do aplicativo móvel Funcionalidade. 2014. Dissertação (Mestrado em Ensino de Ciências na Educação Básica) - Universidade Grande Rio, Duque de Caxias, 2014.

OLIVEIRA, F. T. A inviabilidade do uso das tecnologias da informação e comunicação no contexto escolar: o que contam os professores de matemática? 2014. Dissertação (Mestrado em Educação Matemática)- Universidade Estadual Paulista, Rio Claro, 2014.

OLIVEIRA, G. P.; MARCELINO, S. B. Adquirir Fluência e Pensar com Tecnologias em Educação Matemática: Uma proposta com o software superlogo. Educação Matemática e Pesquisa, São Paulo, v. 17, n. 4, p. 816-842, 2015.

OZAKI, A. M.; VASCONCELLOS, E. A Revolução Digital. p.115-150. In: Sociedade da informação: os desafios da era da colaboração e da gestão do conhecimento. Organizadores: POLIZELLI, D. L.; OZAKI, A. M. São Paulo: Saraiva, 2008.

PAPERT, S. Mindstorms: children, computers and powerful ideas. New York: Basic books, 1980.

PAULO, R. M.; FIRME, I. C. O Programa Acessa Escola: um Espaço para Atuação com as TIC. In: CONGRESSO INTERNACIONAL DAS TIC NA EDUCAÇÃO, 2014, Lisboa/Portugal. Anais...Lisboa/Portugal: [s.n.], 2014.

PERALTA, P. F. Utilização das Tecnologias Digitais por Professores de Matemática: um olhar para a região de São José do Rio Preto. 2015. Dissertação (Mestrado em Educação Matemática). Universidade Estadual Paulista, Rio Claro, 2015.

RIBAS, A. S.; SILVA, S. C. R.; GALVÃO, J. R. Possibilidades de usar o telefone celular como ferramenta educacional para mediar práticas do ensino de Física: uma revisão de literatura. In: SIMPÓSIO NACIONAL DE ENSINO DE CIÊNCIAS E TECNOLOGIA, 2012, Ponta Grossa. Anais... Ponta Grossa: SINECT, 2012. p. $1-12$.

ROMANELLO, L. A. Potencialidades do uso do celular na sala de aula: atividades investigativas para o ensino de função. 2016. Dissertação (Mestrado em Educação Matemática) - Universidade Estadual Paulista, Rio Claro, 2016.

SANTOS, W. J. ; SILVA, I. P. Potencialidades do filme de ficção Avatar para a alfabetização científica dos sujeitos no contexto da educação básica. In: Amazônia - Revista de Educação em Ciências e Matemática - v.13. 2017. p.51-63.

SCHEFFER, N. F. Sensores, Informática e o Corpo: a noção de movimento no ensino fundamental. 2001. Tese (Doutorado em Educação Matemática) - Universidade Estadual Paulista, Rio Claro, 2001.

SCUCUGLIA, R. A Investigação do Teorema Fundamental do Cálculo com Calculadoras Gráficas. 2006. Dissertação (Mestrado em Educação Matemática), Universidade Estadual Paulista, Rio Claro, 2006. 
SELVA, A. C. V.; BORBA, R. E. S. R. O uso da calculadora nos anos iniciais do ensino fundamental. Belo Horizonte: Autêntica, 2010.

SILVA, E. C.; MEDEIROS, D. O.; MORELATTI, M. R. M. Avaliação dos laboratórios de informática das escolas estaduais de Presidente Prudente no contexto do programa acessa escola. In: Seminário Internacional de Observatórios de Educação e Formação, I., 2014, Porto. Anais...Porto - Portugal: [s.n.], 2014.

SOUTO, D. L. P. Transformações Expansivas em um Curso de Educação Matemática a Distância online. 2013. Tese (Doutorado em Educação Matemática) - Universidade Estadual Paulista, Rio Claro, 2013.

TORQUATO, C. Prefácio. p.9-13. In: Sociedade da Informação: os desafios da era da colaboração e da gestão do conhecimento. Organizadores: POLIZELLI, D. L.; OZAKI, A. M. São Paulo: Saraiva, 2008.

URDANETA, S. C. D.; GONZALEZ, J. L. P.; CASTILLO, A. D. Interpretação geométrica dos signos das razões trigonométricas com Geogebra. In: Amazônia - Revista de Educação em Ciências e Matemática - v.13, 2017. p.78-89.

VALENTE, J. A. Mudanças na Sociedade, Mudanças na Educação: O Fazer e o Compreender. p.14-37. In: O Computador na sociedade do conhecimento. Campinas: Gráfica UNICAMP, 1993.

ZAMPIERI, M. T.; JAVARONI, S. L. Formação Continuada de Professores de Matemática: Possibilidade de um curso semipresencial. In: SIMPÓSIO INTERNACIONAL DE EDUCAÇÃO A DISTÂNCIA, II, 2014, São Carlos. Anais... São Carlos: UFSCar, 2014. 